\title{
Comparisons of Neuronal and Excitatory Network Properties between the Rat Brainstem Nuclei that Participate in Vertical and Horizontal Gaze Holding
}

\author{
Yasuhiko Saito, ${ }^{1,2}$ Taketoshi Sugimura, ${ }^{1}$ and Yuchio Yanagawa ${ }^{2,3}$
}

DOI:http://dx.doi.org/10.1523/ENEURO.0180-17.2017

${ }^{1}$ Department of Neurophysiology, Nara Medical University, Kashihara, Nara 634-8521, Japan, ${ }^{2}$ Department of Genetic and Behavioral Neuroscience, Gunma University Graduate School of Medicine, Maebashi, Gunma 371-8511, Japan, and ${ }^{3}$ Japan Science and Technology Agency, Core Research for Evolutional Science and Technology (CREST),

Sanbancho, Chiyoda-ku, Tokyo 102-0075, Japan

\section{Visual Abstract}

\section{Cellular properties}

Afterhyperpolarization profiles
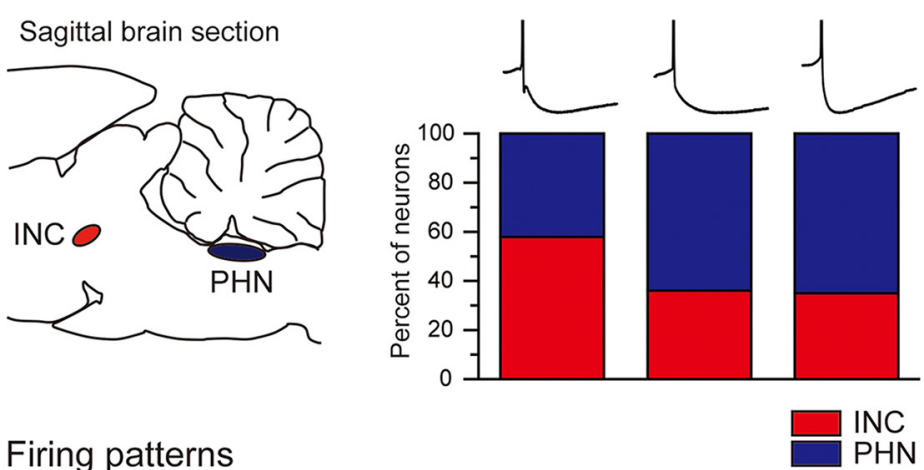

Firing patterns

\section{Network properties}
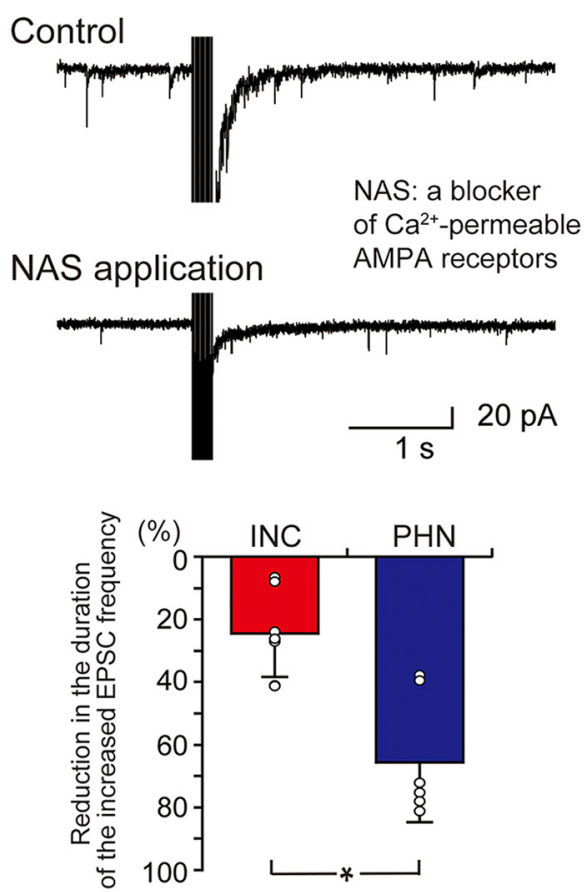

\section{Significance Statement}

Gaze holding is controlled primarily by neural structures including the prepositus hypoglossi nucleus (PHN) for horizontal gaze and the interstitial nucleus of Cajal (INC) for vertical gaze. In this study, to verify whether the neural structure of the INC is similar to that of the PHN, we compared the neuronal and network properties between the INC and PHN. The overall distributions of INC neurons based on their electrophysiological properties were different from those of PHN neurons. The local excitatory networks that activated the sustained EPSC responses were present in both the INC and PHN, but their activation mechanisms including the contribution of $\mathrm{Ca}^{2+}$-permeable AMPA (CP-AMPA) receptors differed between the INC and PHN. 
Gaze holding is primarily controlled by neural structures including the prepositus hypoglossi nucleus (PHN) for horizontal gaze and the interstitial nucleus of Cajal (INC) for vertical and torsional gaze. In contrast to the accumulating findings of the $\mathrm{PHN}$, there is no report regarding the membrane properties of INC neurons or the local networks in the INC. In this study, to verify whether the neural structure of the INC is similar to that of the PHN, we investigated the neuronal and network properties of the INC using whole-cell recordings in rat brainstem slices. Three types of afterhyperpolarization (AHP) profiles and five firing patterns observed in PHN neurons were also observed in INC neurons. However, the overall distributions based on the AHP profile and the firing patterns of INC neurons were different from those of PHN neurons. The application of burst stimulation to a nearby site of a recorded INC neuron induced an increase in the frequency of spontaneous EPSCs. The duration of the increased EPSC frequency of INC neurons was not significantly different from that of PHN neurons. The percent of duration reduction induced by $\mathrm{Ca}^{2+}$-permeable AMPA (CP-AMPA) receptor antagonist was significantly smaller in the INC than in the PHN. These findings suggest that local excitatory networks that activate sustained EPSC responses also exist in the INC, but their activation mechanisms including the contribution of CP-AMPA receptors differ between the INC and the PHN.

Key words: Ca2+-permeable AMPA receptor; firing pattern; interstitial nucleus of Cajal; local excitatory network; neural integrator; prepositus hypoglossi nucleus

\section{Introduction}

Holding the eye steady after movement is essential for stably capturing a visual target by the foveal centralis of the retina. Gaze holding is generated primarily by neural structures that function as an oculomotor neural integrator, transforming transient burst signals that are proportional to eye or head velocity into sustained signals that are proportional to eye position (Robinson, 1975, 1989; Fukushima et al., 1992; Fukushima and Kaneko 1995; Moschovakis 1997; Leigh and Zee, 2015). In the oculomotor system, horizontal and vertical (and torsional) eye movements are controlled separately by different brain areas such as the paramedian pontine reticular formation and the rostral interstitial nucleus of the medial longitudinal fasciculus, respectively (Miller, 1985; Büttner and Büttner-Ennever, 2006). Similar to the eye movement system, oculomotor neural integrators are separated into the prepositus hypoglossi nucleus (PHN) for horizontal gaze and the interstitial nucleus of Cajal (INC) for vertical gaze

Received May 22, 2017; accepted August 29, 2017; First published September 4, 2017.

The authors declare no competing financial interests.

Author contributions: Y.S. designed research; Y.S., S.T., and Y.Y. performed research; Y.S. and Y.Y. analyzed data; Y.S. and Y.Y. wrote the paper.

This work was supported by funding from the Takeda Science Foundation, a Grant-in-Aid for Scientific Research on Innovative Areas (Comprehensive Brain Science Network) from Ministry of Education, Culture, Sports, Science and Technology (MEXT), a Grant-in-Aid for Scientific Research from Japan Society for the Promotion of Science (JSPS), and a grant from the Cooperative Program of the National Institute for Physiological Sciences, Japan.

Acknowledgements: We thank Ryosuke Kaneko, Keiko Harada, and Ayako Morita for technical assistance; the members of our labs in Gunma University and Nara Medical University for helpful comments; and the staff of the Institutes of Experimental Animal Research in Gunma and Nara Medical Universities for technical support. We also thank the National BioResource Project for the Rat in Japan (http://www.anim.med.kyoto-u.ac.jp/NBR/) for providing the VGAT-Venus rat strains [W-Tg(SIc32a1-YFP*)2Yyan].

Correspondence should be addressed to Yasuhiko Saito, Ph.D., Department of Neurophysiology, Nara Medical University, 840 Shijo-cho, Kashihara, Nara 634-8521, Japan, E-mail: syasu@naramed-u.ac.jp.

DOI:http://dx.doi.org/10.1523/ENEURO.0180-17.2017

Copyright (C) 2017 Saito et al.

This is an open-access article distributed under the terms of the Creative Commons Attribution 4.0 International license, which permits unrestricted use, distribution and reproduction in any medium provided that the original work is properly attributed.
(Fukushima, 1987, 1991; Fukushima et al., 1992; Fukushima and Kaneko, 1995; Moschovakis, 1997; Leigh and Zee, 2015). The PHN is located in the pontomedullary region and contains neurons of various sizes (McCrea and Horn, 2006), whereas the INC is located in the rostral mesencephalon and consists of scattered neurons (Rutherford and Gwyn, 1982; Fukushima, 1987). Both nuclei contain a variety of neurons that encode signals related to eye movements, including eye position (PHN, LopezBarneo et al., 1982; Delgado-García et al., 1989; Escudero et al., 1992; McFarland and Fuchs, 1992; INC, King et al., 1981; Fukushima et al., 1990a, b; Crawford et al., 1991; Helmchen et al., 1998; Chimoto et al., 1999). Although several models have been proposed regarding the neural mechanisms of signal transformation in the neural integrator (Cannon et al., 1983; Galiana and Outerbridge, 1984; Cannon and Robinson, 1985; Arnold and Robinson, 1997; Draye et al., 1997; Seung et al., 2000; Major and Tank, 2004), the detailed mechanisms have not been elucidated experimentally, except for findings reported in a series of studies in goldfish (Aksay et al., 2001, 2003, 2007; Lee et al., 2015).

Apart from the findings of neurons that show spiking in relation to eye movements, intracellular recordings using in vitro slice preparations have demonstrated the presence of a variety of neurons that exhibit distinct electrophysiological membrane properties in the PHN (guinea pig, Bobker and Williams, 1990, 1995; Idoux et al., 2006, 2008; mouse, Kolkman et al., 2011; rat, Shino et al., 2008, 2011; Saito et al., 2012, 2015; Saito and Yanagawa, 2013; Zhang et al., 2014). Idoux et al. (2006) found a unique neuron type (type D) that exhibited clusters of action potentials intermingled with subthreshold membrane oscillations and bistable plateau-like responses through an NMDA-dependent mechanism, which may be used for the robustness of neural activities in the integrator network. Furthermore, a previous study demonstrated the presence of local excitatory networks in the PHN (Saito and Yanagawa, 2010). These networks were activated via $\mathrm{Ca}^{2+}$-permeable AMPA (CP-AMPA) receptors in addition to NMDA receptors and participated in sustained activity that may code eye position. In contrast to the accumulating findings of the neuronal and network properties in the 
$\mathrm{PHN}$, there is no report regarding the membrane properties of INC neurons and the local networks in the INC. The comparison of the neuronal and network properties between the PHN and the INC can provide information regarding whether the mechanisms of the neural integrators are common or different in the horizontal and vertical systems. In the present study, to clarify whether the neural structure of the INC is similar to that of the PHN, we investigated the neuronal and network properties of the INC using whole-cell recordings in rat brainstem slices. Furthermore, we compared the results obtained from the INC to those obtained from previous studies of the PHN (Shino et al., 2008; Saito and Yanagawa, 2010; Zhang et al., 2014; Saito et al., 2015) to verify (1) whether the neuronal distributions classified by membrane properties in the INC are similar to those in the PHN and (2) whether the local excitatory networks that induce the sustained activity are also present in the INC.

\section{Materials and Methods}

All experimental procedures were approved by the Animal Care and Experimentation Committee of Gunma University and the Animal Care Committee of Nara Medical University, and the experiments were conducted in accordance with the Guidelines outlined by the United States National Institutes of Health regarding the care and use of animals for experimental research. Every effort was made to minimize suffering and the number of animals used in these experiments. The data of INC neurons and networks were newly obtained and analyzed in this study; however, the results of the PHN were reanalyzed using data obtained in our previous studies (Shino et al., 2008; Saito and Yanagawa, 2010; Saito et al., 2015).

\section{Animals and histologic procedures}

The data were obtained from wild-type Wistar rats and vesicular GABA transporter (VGAT)-Venus transgenic rats (Uematsu et al., 2008; Shino et al., 2011). In VGAT-Venus rats, inhibitory neurons that expressed a fluorescent protein Venus (Nagai et al., 2002) were easily identifiable with fluorescence microscopy. A total of 18 young wild-type and 11 VGAT-Venus rats [17-21 postnatal days (PND)] of either sex were used in the present study. In addition, two double transgenic rats were used for histologic observation of inhibitory and cholinergic neurons in the INC and $\mathrm{PHN}$. The double transgenic rats were generated by crossing the choline acetyltransferase (ChAT)-tdTomato and VGAT-Venus transgenic rats (Saito et al., 2015; Zhang et al., 2016). These rats (21 PND) were transcardially perfused with $0.05 \mathrm{M}$ phosphate buffer (PB, pH 7.4), followed by $4 \%$ paraformaldehyde in PB under deep anesthesia induced via isoflurane inhalation (vaporized with oxygen) followed by intraperitoneal injection of sodium pentobarbital $(>50 \mathrm{mg} / \mathrm{kg})$. The brain areas including the $\mathrm{PHN}$ and INC were dissected and cut frontally into $50-\mu \mathrm{m}$ sections using a Microslicer (Dosaka EM). The sections were mounted on MAS-coated slides (Matsunami Glass) using an anti-fade medium (ProLong Gold anti-fade reagent, Invitrogen). The neurons were observed under a fluorescence microscope (BX60, Olympus). In this prepa- ration, inhibitory and cholinergic neurons express yellowgreen and red fluorescence, respectively.

\section{Slice preparation and whole-cell recording}

Wild-type or VGAT-Venus rats were decapitated under deep anesthesia with isoflurane, and the brain was quickly removed. Frontal slices (250 or $400 \mu \mathrm{m}$ thick), including the INC were sliced using a Microslicer (Pro 7, Dosaka EM). After the slices were incubated for $>1 \mathrm{~h}$ at room temperature in an extracellular solution containing 125 $\mathrm{mM} \mathrm{NaCl}, 2.5 \mathrm{mM} \mathrm{KCl}, 2 \mathrm{mM} \mathrm{CaCl}, 1 \mathrm{mM} \mathrm{MgCl}_{2}, 1.25$ $\mathrm{mM} \mathrm{NaH} \mathrm{PO}_{4}, 26 \mathrm{mM} \mathrm{NaHCO}_{3}$, and $25 \mathrm{mM}$ glucose and aerated with $95 \% \mathrm{O}_{2}$ and $5 \% \mathrm{CO}_{2}(\mathrm{pH} 7.4)$, they were transferred to a submerged recording chamber on an upright microscope (Leica DM LFS, Leica) and continuously perfused with extracellular solution at a rate of 5 $\mathrm{ml} / \mathrm{min}$. The bath temperature was kept at $30-32^{\circ} \mathrm{C}$ using an in-line heater (SH-27A, Warner Instruments). Wholecell current-clamp and voltage-clamp recordings were performed using an EPC-8 patch clamp amplifier (HEKA). Patch pipettes were prepared from borosilicate glass capillaries and filled with a $\mathrm{K}^{+}$-based internal solution containing $120 \mathrm{mM}$ K-methylsulfate, $10 \mathrm{mM} \mathrm{KCl}, 0.2 \mathrm{mM}$ EGTA, 2 mM Mg-ATP, $0.3 \mathrm{mM}$ Na-GTP, $10 \mathrm{mM}$ HEPES, $10 \mathrm{mM} \mathrm{Na} \mathrm{N}_{2}$-phosphocreatine, and $0.1 \mathrm{mM}$ spermine, $\mathrm{pH}$ adjusted to 7.3 with $\mathrm{KOH}$ for current-clamp experiments. The INC was identified by referring to a rat brain atlas (Paxinos and Watson, 2007). Although the medial boundary of the INC was easily defined by the medial longitudinal fasciculus, the lateral boundary of the INC was not as clear. Therefore, we did not attempt to record from the neurons that located near the lateral boundary. The range between -6.12 and $-5.04 \mathrm{~mm}$ from the bregma shown in the atlas corresponded to the range of slices used in this study. However, the rats used in this study were younger than those used in the atlas, and thus, we used two to three slices (250 $\mu \mathrm{m}$ thick) or one to two slices (400 $\mu \mathrm{m}$ thick) per animal. In voltage-clamp experiments, we used a $\mathrm{Cs}^{+}$-based internal solution containing $145 \mathrm{mM}$ Csgluconate, $5 \mathrm{mM} \mathrm{CsCl}, 0.2 \mathrm{mM}$ EGTA, $2 \mathrm{mM}$ Mg-ATP, 0.3 $\mathrm{mM}$ Na-GTP, $10 \mathrm{mM}$ HEPES, $0.1 \mathrm{mM}$ spermine, and 5 $\mathrm{mM}$ lidocaine $N$-ethyl bromide $(\mathrm{QX}-314), \mathrm{pH}$ 7.3. The osmolarity of the internal solution was $280-290 \mathrm{mOsm} / \mathrm{l}$ and the resistance of patch electrodes was 5-8 $\mathrm{M} \Omega$ in the bath solution. Voltage and current signals were low-pass filtered at $3 \mathrm{kHz}$ and digitized at $10 \mathrm{kHz}$. The measured liquid junction potential $\left(\mathrm{K}^{+}\right.$-based internal solution $=-5$ $\mathrm{mV}, \mathrm{Cs}^{+}$-based internal solution $=-10 \mathrm{mV}$ ) was corrected. Neurons displaying a membrane potential below $-50 \mathrm{mV}$ immediately after patch membrane rupture and action potential peaks higher than $0 \mathrm{mV}$ were used for further analyses. When voltage responses to current pulses were investigated in current-clamp mode, depolarizing current pulses (up to $400 \mathrm{pA}$ in 20- to $40-\mathrm{pA}$ increments, $400 \mathrm{~ms}$ in duration) were injected into the neurons. In these neurons, the membrane potential was maintained at -85 to $-75 \mathrm{mV}$ before the current pulses via the injection of constant currents. For analyses of the action potential profiles, including the afterhyperpolarization (AHP) profiles, the depolarizing current pulses were 
adjusted to induce one action potential over $400 \mathrm{~ms}$. When current recordings were performed in voltageclamp mode, the holding potential was set to $-75 \mathrm{mV}$. For the application of the high frequency stimulation (burst stimulation), electrical stimulation of 20 cathodal squarewave pulses (10-25 $\mu \mathrm{A}, 100 \mu \mathrm{s}$ in duration) was applied in the vicinity of a recorded neuron using a glass micropipette that was filled with extracellular solution. To determine the stimulation site, we scanned 8-10 different sites around a recorded neuron with the application of burst stimulation to each site. A site where the current responses of the neuron appeared to be the largest was determined as an appropriate stimulation site. The approximate distance between each recorded neuron and the stimulation electrode was 30-80 $\mu \mathrm{m}$. The burst stimulation was applied to INC neurons in which spontaneous EPSCs occurred at a frequency of $>1$ event/s. The data were acquired using a pClamp9 system (Molecular Devices). Strychnine hydrochloride and 1-naphthyl acetyl spermine (NAS) was purchased from Sigma-Aldrich Japan, and other drugs including pictrotoxin were purchased from Wako Pure Chemical Industries.

\section{Data analysis}

Off-line analysis was performed with AxoGraph X software (RRID: SCR_014284) and the Kaleidagraph (RRID: SCR_014980). The input resistance was estimated based on the voltage change induced by a hyperpolarizing current pulse of $-40 \mathrm{pA}$ applied at a membrane potential of -55 to $-65 \mathrm{mV}$. The amplitude of the AHP was estimated as the difference between the most negative membrane potential of the AHP and the action potential threshold, which was defined as the membrane potential at which the derivative of the voltage trace reached $10 \mathrm{~V} / \mathrm{s}$. To clarify which neurons were predominant in each AHP profile or each firing pattern between the INC and the $\mathrm{PHN}$, we presented the proportion of INC and PHN neurons that exhibited each AHP profile or each firing pattern (see Figures 1, F and $G$, and $3, C$ and $D$ ). The total number of INC and PHN neurons was each normalized to be 100 , and the percentages of neurons that exhibited each AHP profile or each firing pattern were obtained by dividing the number of either INC or PHN neurons by the sum of the number of INC or PHN neurons, respectively, exhibiting each property. EPSCs were determined when the peak of the inward current was more than three times the SD of the baseline noise before burst stimulation. To detect EPSCs after burst stimulation, an inward deflection of the baseline, which occurred immediately after burst stimulation and returned to the origin by $\sim 300 \mathrm{~ms}$ (see Figure $4 A 1$ below), was removed by the subtraction of the trace filtered up to $10 \mathrm{~Hz}$ from the original trace. The EPSC frequencies before and after burst stimulation were measured from recordings of $2 \mathrm{~s}$ before and $1 \mathrm{~s}$ after burst stimulation, respectively. To estimate the duration of the increased EPSC frequency, we generated a histogram of EPSC frequency versus time (see Figure $4 A$ below). Using the histogram, the duration was defined as the time period from when burst stimulation was terminated to when the averaged value of three adjacent bins (corresponding to
$300 \mathrm{~ms}$ ) became equal to or smaller than the average baseline EPSC frequency before burst stimulation. When the effect of NAS on the EPSC responses was investigated, we measured the amplitude of EPSC and the duration of the increased EPSC frequency. Because the application of NAS usually reduced the baseline noise, low amplitude EPSCs were detected in the presence of NAS. Therefore, a simple comparison of the average EPSCs in the presence of NAS to those in the control may lead to overestimation. Instead, we focused on the maximum EPSC before burst stimulation and estimated the reduction in the amplitude of the maximum EPSC by the application of NAS. The maximum EPSC of the recorded neuron was obtained by averaging the maximum EPSC in each of five recordings. All values are shown as the mean $\pm S D$, and the error bars in the figures represent the SD. The number $(n)$ refers to the number of neurons analyzed unless otherwise noted. The statistical analysis was performed using unpaired or paired Student's $t$ tests for normally distributed data and Mann-Whitney tests for the data that did not follow a normal distribution. Data normality was determined using the Shapiro-Wilk test. StatView software (Hulinks) and JMP software (RRID: SCR_014242) were used for the analyses. A post hoc power analysis was performed using G*Power3 software (http://www.gpower.hhu.de/; RRID: SCR_013726; Faul et al., 2007). Statistical significance was determined at the level of $p<0.05$. Detailed results of the statistical analyses are shown in Table 1.

\section{Results}

\section{AHP profiles and firing patterns of INC neurons}

In previous studies of PHN neurons (Shino et al., 2008, 2011; Zhang et al., 2014; Saito et al., 2015), AHP profiles and firing patterns, which are the parameters that determine the firing behavior and the output properties of neurons, respectively, were characterized. In PHN neurons, AHP profiles and firing patterns were classified into three and six types, respectively. The three AHP profiles included (1) an AHP that contained a slow component and afterdepolarization (ADP), (2) an AHP that contained a slow component (S+), and (3) an AHP that lacked a slow component (S-). The six firing patterns included (1) a repetitive firing pattern with relatively constant interspike intervals (CON), (2) a firing pattern with a delay in the generation of the first spike because of transient hyperpolarization following the onset of the depolarizing pulse (LAT), (3) a firing pattern that exhibited a cluster of two or more spikes because of a low-threshold calcium spike (LTS), (4) a firing pattern in which the first interspike interval was longer compared with the second interval (FIL), (5) a firing pattern that exhibited few spikes during the 400-ms current injection, despite sufficient membrane depolarization (LFR), and (6) a firing pattern that exhibited an oscillatory property (OSC). Therefore, we investigated whether these AHP profiles and firing patterns are also applicable to INC neurons and which AHP profiles and firing patterns were preferentially found in INC neurons. When we performed whole-cell recordings from randomly sampled neurons $(n=120)$ in the INC (Fig. 1A), the three 
A

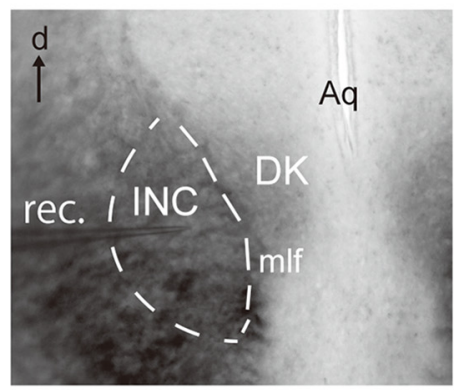

B

$2 \mathrm{~S}+$

3 S-
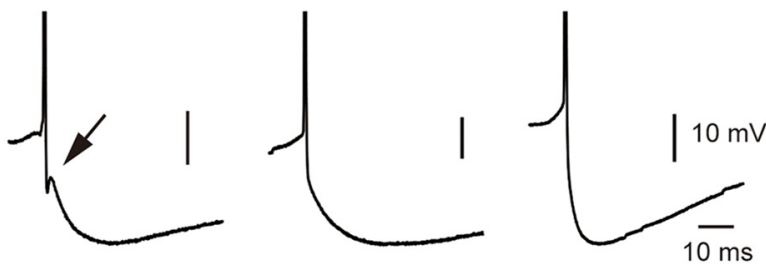

C

$1 \mathrm{CON}$

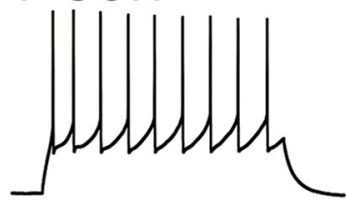

2 LAT

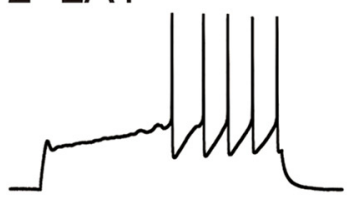

D

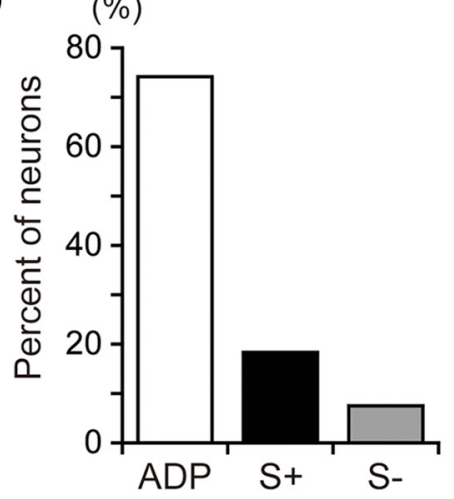

F

(\%)

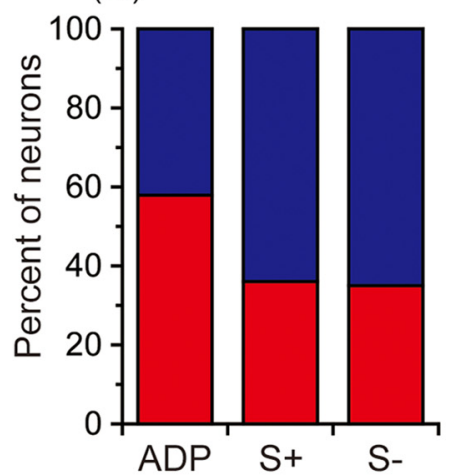

3 LTS

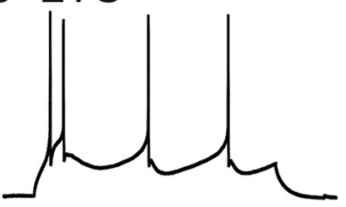

4 LTS subtype

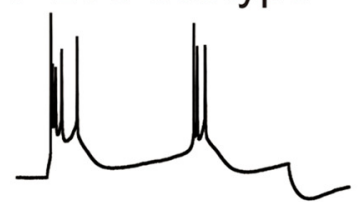

E

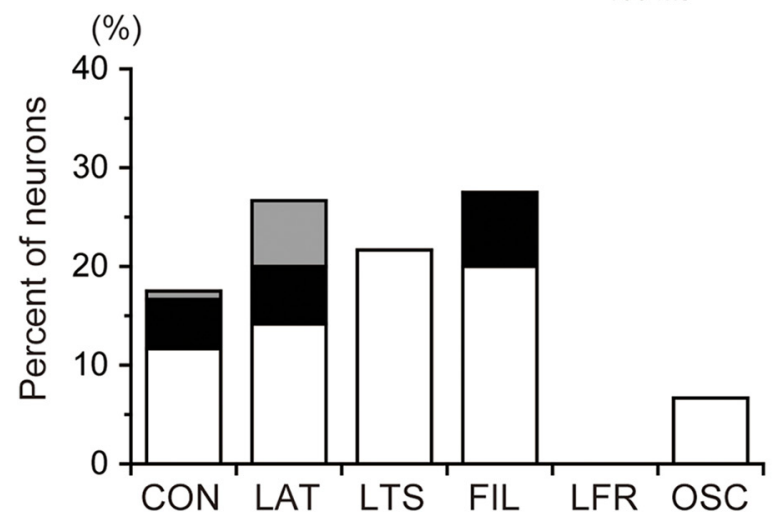

5 FIL

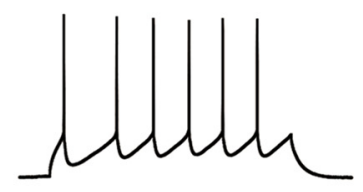

6 OSC

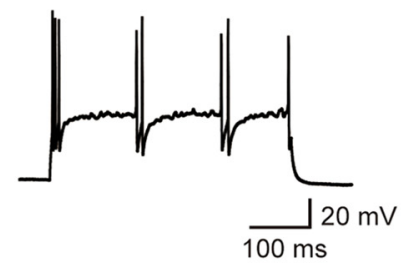

G

(\%)

$\square$ INC

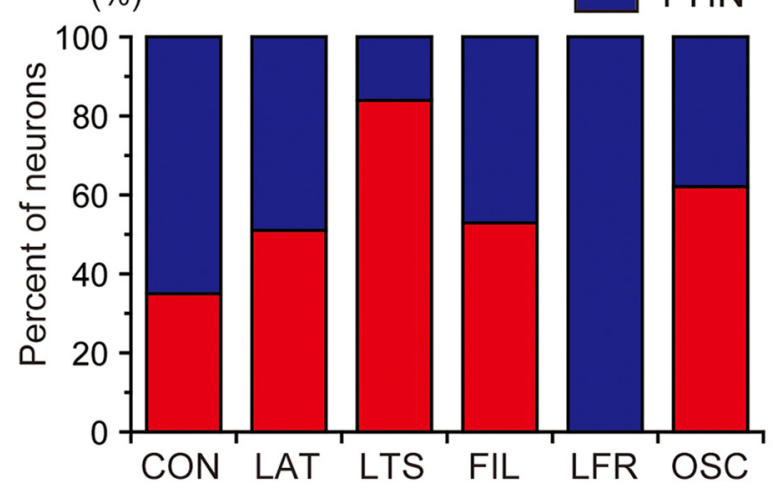

Figure 1. AHP profiles and firing patterns of INC neurons. A, Photomicrograph of a frontal section of the INC. The dashed line shows the rough boundary of the INC. DK, nucleus of Darkschewitsch; mlf, medial longitudinal fasciculus; Aq, aqueduct; rec, recording pipette; d, dorsal. B, AHP profiles. (1) AHP with ADP (arrow), (2) AHP with a slow component (S+), and (3) AHP without a slow 
continued

component (S-). C, firing patterns. (1) Continuous spiking pattern (CON), (2) late spiking pattern (LAT), (3) low-threshold calcium spike pattern (LTS), (4) a subtype of LTS that exhibited oscillatory burst firing, (5) longer first interspike interval pattern (FIL), and (6) oscillatory firing pattern (OSC). The white, black and gray bars represent the ADP, S+ and S- profiles, respectively. $\boldsymbol{D}, \boldsymbol{E}$, distributions of the AHP profiles $(\boldsymbol{D})$ and the firing patterns $(\boldsymbol{E})$ among INC neurons. $\boldsymbol{F}$, $\boldsymbol{G}$, The proportion of INC (red) and PHN (blue) neurons that exhibited each AHP profile $(\boldsymbol{F})$ or firing pattern $(\boldsymbol{G})$. The percentages of neurons that exhibited each AHP profile or each firing pattern was normalized to the total percentages of neurons exhibiting each property.

types of the AHP profile were observed in the neurons (Fig. 1B). The distribution of INC neurons classified by AHP profiles revealed that $>70 \%$ of recorded INC neurons exhibited the ADP profile (Fig. 1D). When the firing patterns were analyzed, five firing patterns, namely, the CON, LAT, LTS, FIL, and OSC patterns, were observed (Fig. 1C). Interestingly, three neurons showed repeated burst firing during the application of current pulses (Fig. 1C4), which had not been observed in PHN neurons.
However, all the neurons with this firing pattern exhibited transient burst firing that was caused by LTS above the threshold of spike generation. We checked the position of these neurons after the recordings and confirmed that all these neurons were definitely within the INC. Therefore, these neurons were regarded as a subtype of the LTS type. INC neurons that exhibited the LFR pattern were not observed in this study. Figure $1 E$ shows the distribution of INC neurons classified based on firing patterns. Except

Table 1. Statistical test

\begin{tabular}{|c|c|c|}
\hline $\begin{array}{l}\text { Panel, parameter } \\
\text { (bivariate) }\end{array}$ & $\begin{array}{l}\text { Distribution } \\
\text { and } p \text { value (type of test) }\end{array}$ & $\begin{array}{l}\text { Power } \\
(\alpha=0.05)\end{array}$ \\
\hline $\begin{array}{l}\text { Figure 3E2, frequency of SMOCs } \\
\text { (INC vs PHN) }\end{array}$ & $\begin{array}{l}\text { Non-normal } \\
0.081 \text { (Mann-Whitney test) }\end{array}$ & 0.389 \\
\hline $\begin{array}{l}\text { Figure } 4 B \text {, duration } \\
\text { (INC vs PHN) }\end{array}$ & $\begin{array}{l}\text { Normal } \\
0.053 \text { (unpaired } t \text { test) }\end{array}$ & 0.627 \\
\hline $\begin{array}{l}\text { Figure } 4 C, \mathrm{~F}_{\text {post }} / \mathrm{F}_{\text {pre }} \\
\text { (INC vs PHN) }\end{array}$ & $\begin{array}{l}\text { Non-normal } \\
0.016 \text { (Mann-Whitney test) }\end{array}$ & 0.801 \\
\hline $\begin{array}{l}\text { Figure 4D2, max. EPSC amplitude } \\
\text { (control vs NAS) }\end{array}$ & $\begin{array}{l}\text { Normal } \\
0.0005 \text { (paired } t \text { test) }\end{array}$ & 1.000 \\
\hline $\begin{array}{l}\text { Figure 4D3, duration } \\
\text { (control vs NAS) }\end{array}$ & $\begin{array}{l}\text { Normal } \\
0.011 \text { (paired } t \text { test) }\end{array}$ & 0.937 \\
\hline $\begin{array}{l}\text { Figure } 4 E \text {, reduction in max. EPSC amp. } \\
\text { (INC vs PHN) }\end{array}$ & $\begin{array}{l}\text { Non-normal } \\
0.098 \text { (Mann-Whitney test) }\end{array}$ & 0.520 \\
\hline $\begin{array}{l}\text { Figure } 4 F \text {, reduction in duration } \\
\text { (INC vs } \mathrm{PHN} \text { ) }\end{array}$ & $\begin{array}{l}\text { Non-normal } \\
0.0087 \text { (Mann-Whitney test) }\end{array}$ & 0.997 \\
\hline $\begin{array}{l}\text { Table 2, input capacitance } \\
(\mathrm{V}+\text { INC vs V+ PHN) }\end{array}$ & $\begin{array}{l}\text { Non-normal } \\
<0.0001 \text { (Mann-Whitney test) }\end{array}$ & 1.000 \\
\hline $\begin{array}{l}\text { Table } 2 \text {, input resistance } \\
(\mathrm{V}+\mathrm{INC} \text { vs } \mathrm{V}+\mathrm{PHN})\end{array}$ & $\begin{array}{l}\text { Non-normal } \\
<0.0001 \text { (Mann-Whitney test) }\end{array}$ & 1.000 \\
\hline $\begin{array}{l}\text { Table 2, spike amplitude } \\
\text { (V+ INC vs V+ PHN) }\end{array}$ & $\begin{array}{l}\text { Non-normal } \\
0.106 \text { (Mann-Whitney test) }\end{array}$ & 0.517 \\
\hline $\begin{array}{l}\text { Table } 2 \text {, spike half-width } \\
(\mathrm{V}+\text { INC vs } \mathrm{V}+\mathrm{PHN})\end{array}$ & $\begin{array}{l}\text { Non-normal } \\
\text { 0.0097(Mann-Whitney test) }\end{array}$ & 0.689 \\
\hline $\begin{array}{l}\text { Table 2, AHP amplitude } \\
(\mathrm{V}+\text { INC vs V+ PHN) }\end{array}$ & $\begin{array}{l}\text { Non-normal } \\
0.0007 \text { (Mann-Whitney test) }\end{array}$ & 0.950 \\
\hline $\begin{array}{l}\text { Table } 2 \text {, spontaneous firing rate } \\
(\mathrm{V}+\text { INC vs } \mathrm{V}+\mathrm{PHN})\end{array}$ & $\begin{array}{l}\text { Non-normal } \\
0.559 \text { (Mann-Whitney test) }\end{array}$ & 0.305 \\
\hline $\begin{array}{l}\text { Table } 2, \mathrm{CV} \text { of interspike interval } \\
(\mathrm{V}+\text { INC vs } \mathrm{V}+\mathrm{PHN})\end{array}$ & $\begin{array}{l}\text { Non-normal } \\
0.036 \text { (Mann-Whitney test) }\end{array}$ & 0.668 \\
\hline $\begin{array}{l}\text { Table 2, input capacitance } \\
\text { (V- INC vs D- PHN) }\end{array}$ & $\begin{array}{l}\text { Non-normal } \\
0.027 \text { (Mann-Whitney test) }\end{array}$ & 0.380 \\
\hline $\begin{array}{l}\text { Table 2, input resistance } \\
\text { (V- INC vs D- PHN) }\end{array}$ & $\begin{array}{l}\text { Non-normal } \\
0.0002 \text { (Mann-Whitney test) }\end{array}$ & 0.991 \\
\hline $\begin{array}{l}\text { Table 2, spike amplitude } \\
\text { (V- INC vs D- PHN) }\end{array}$ & $\begin{array}{l}\text { Normal } \\
<0.0001 \text { (unpaired } t \text { test) }\end{array}$ & 0.989 \\
\hline $\begin{array}{l}\text { Table 2, spike half-width } \\
\text { (V- INC vs D- PHN) }\end{array}$ & $\begin{array}{l}\text { Non-normal } \\
<0.0001 \text { (Mann-Whitney test) }\end{array}$ & 0.961 \\
\hline $\begin{array}{l}\text { Table 2, AHP amplitude } \\
\text { (V- INC vs D- PHN) }\end{array}$ & $\begin{array}{l}\text { Non-normal } \\
0.0063 \text { (Mann-Whitney test) }\end{array}$ & 0.872 \\
\hline $\begin{array}{l}\text { Table 2, spontaneous firing rate } \\
\text { (V- INC vs D- PHN) }\end{array}$ & $\begin{array}{l}\text { Non-normal } \\
0.108 \text { (Mann-Whitney test) }\end{array}$ & 0.284 \\
\hline $\begin{array}{l}\text { Table 2, CV of the interspike interval } \\
\text { (V- INC vs D- PHN) }\end{array}$ & $\begin{array}{l}\text { Non-normal } \\
0.0003 \text { (Mann-Whitney test) }\end{array}$ & 0.786 \\
\hline
\end{tabular}



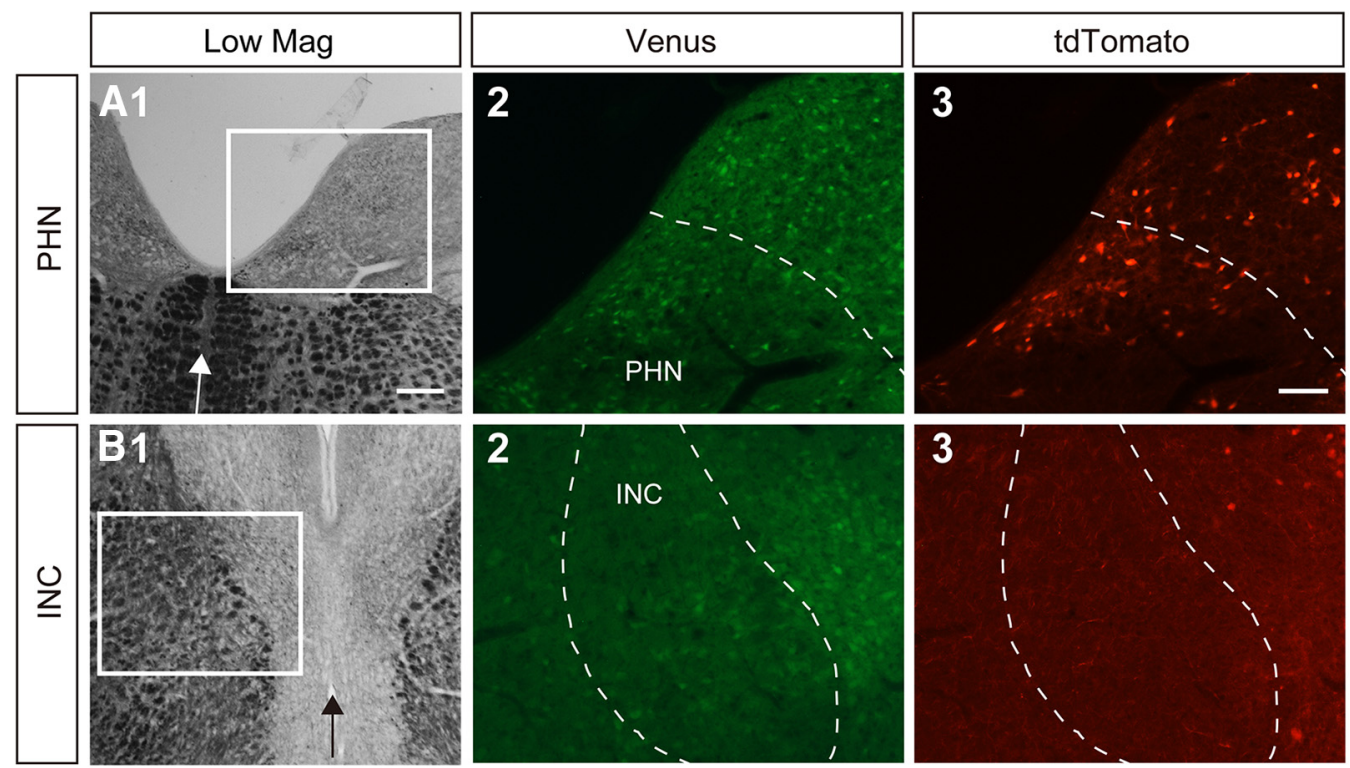

Figure 2. Histologic observation of inhibitory and cholinergic neurons in the INC and the PHN. $\boldsymbol{A 1}$, B1, Low-magnification photomicrographs of frontal sections that included the INC (A1) and the PHN (B1). Arrow indicates the midline. A2, A3, B2, B3, Fluorescent photomicrographs of the areas outlined by the rectangles in $\boldsymbol{A} \mathbf{1}$ and $\boldsymbol{B} \mathbf{1}$, respectively. The dashed lines indicate the region of the INC $(\boldsymbol{A 2}, \boldsymbol{A 3})$ and the boundary of the MVN and the PHN $(\boldsymbol{B 2}, \boldsymbol{B} 3)$.

for the OSC type, which represented a minor population, no preferential firing type was apparent in INC neurons. To clarify which neurons were predominant in each AHP profile or each firing pattern between the INC and the $\mathrm{PHN}$, we compared the percentage of INC neurons to that of PHN neurons obtained from a previous study (Shino et al., 2008). The percentage of neurons exhibiting the ADP profile was higher in the INC (red) than in the PHN (blue), whereas the percentages of neurons exhibiting the other two profiles were higher in the PHN than in the INC (Fig. 1F). Regarding the distribution of neurons classified based on the firing patterns (Fig. 1G), a higher percentage of PHN neurons exhibited the CON pattern, and a higher percentage of INC neurons exhibited the LTS pattern. As described above, no neuron exhibited the LFR pattern in the INC, although $\sim 10 \%$ of PHN neurons exhibited this pattern.

\section{AHP profiles and firing patterns of excitatory and inhibitory neurons}

In the PHN, cholinergic neurons are present in addition to excitatory glutamatergic neurons and inhibitory GABAergic/glycinergic neurons, which are major neuronal population (McCrea and Horn, 2006). In a previous study using double transgenic rats that were generated by crossing the ChAT-tdTomato and VGAT-Venus transgenic rats, these three types of neurons were identified separately under fluorescence microscopy of brain slices (Saito et al., 2015). In these rats, glutamatergic neurons expressed neither tdTomato nor Venus [double-negative (D-)], cholinergic neurons expressed tdTomato alone, and GABAergic/glycinergic inhibitory neurons expressed Venus alone. The presence of tdTomato-expressing cholinergic neurons and Venus-expressing inhibitory neurons in the PHN was confirmed by observing the fluorescence of the slices obtained from the double transgenic rats (Fig. $2 A)$. On the other hand, a previous study reported no observation of ChAT-positive neurons in the INC (Tago et al., 1989). In support of this finding, we found no INC neurons that expressed tdTomato in ChAT-tdTomato transgenic rats (Fig. 2B3), although a few tdTomatoexpressing neurons were observed near the boundary of the INC. tdTomato-expressing axonal fibers were frequently observed in the INC (Fig. 2B3). Electrophysiological studies showed that stimulation of the INC induced excitatory and inhibitory synaptic potentials in motoneurons of the trochlear and oculomotor nuclei and contralateral INC neurons (Schwindt et al., 1974; Nakao and Shiraishi, 1985; Izawa et al., 2007; Sugiuchi et al., 2013). Immunocytochemical and in situ hybridization studies showed the presence of glutamate decarboxylase (GAD)positive neurons in the INC (Giolli et al., 1985; Horn et al., 2003). We observed Venus-expressing neurons that showed medium-sized somata and a scattered distribution in the INC (Fig. 2B2), which may be comparable to the distribution of GAD-positive neurons (Giolli et al., 1985; Horn et al., 2003). Because the presence of a substantial number of neurons showing neurotransmitter phenotypes other than glutamatergic and GABAergic has not been reported in the INC, the major neuronal populations in the INC are considered to be excitatory, presumed as glutamatergic neurons and inhibitory GABAergic neurons. Therefore, it might be possible that the different neuronal distributions between the INC and the PHN are partly attributed to the absence of cholinergic neurons in the INC. We next focused on excitatory and inhibitory neurons and compared the neuronal distributions between the INC and the PHN. To compare the electrophysiological properties of the inhibitory and excitatory neurons in the INC to those in the PHN, we reanalyzed the data of $\mathrm{V}+$ 
Table 2. Summary of electrophysiological properties of inhibitory and noninhibitory neurons in the INC and the PHN

\begin{tabular}{lllll}
\hline & V+ INC & V + PHN & V- INC & D- PHN \\
Input capacitance $(\mathrm{pF})$ & $56.0 \pm 21.7 * *$ & $31.5 \pm 17.6$ & $54.7 \pm 23.8 *$ & $47.6 \pm 32.5$ \\
Input resistance $(\mathrm{M} \Omega)$ & $423.1 \pm 187.5 * *$ & $662.9 \pm 296.4$ & $358.0 \pm 180.1 * *$ & $572.9 \pm 335.3$ \\
Spike amplitude $(\mathrm{mV})$ & $72.3 \pm 7.8$ & $74.6 \pm 7.0$ & $69.7 \pm 8.4 * *$ & $76.9 \pm 8.9$ \\
Spike half-width $(\mathrm{ms})$ & $0.398 \pm 0.11 * *$ & $0.441 \pm 0.11$ & $0.39 \pm 0.13 * *$ & $0.54 \pm 0.14$ \\
AHP amplitude $(\mathrm{mV})$ & $28.7 \pm 6.1 * *$ & $32.1 \pm 4.9$ & $26.4 \pm 5.5 * *$ & $29.1 \pm 5.0$ \\
Spontaneous firing rate (spikes/s) & $10.4 \pm 7.2$ & $9.2 \pm 4.5$ & $6.1 \pm 5.8$ & $7.1 \pm 4.3$ \\
CV of the interspike interval (\%) & $17.2 \pm 29.3 *$ & $8.8 \pm 12.9$ & $16.3 \pm 19.5 * *$ & $8.3 \pm 13.5$ \\
\hline
\end{tabular}

The analyses were performed on data collected from $70 \mathrm{~V}+$ and $70 \mathrm{~V}$ - PHN neurons and $55 \mathrm{~V}+$ and $55 \mathrm{~V}$ - INC neurons. The CVs of the interspike interval were analyzed in the neurons that fired spontaneously (52 V+ INC, $68 \mathrm{~V}+$ PHN, $40 \mathrm{~V}$ - INC, and $67 \mathrm{D}-\mathrm{PHN})$. Asterisks indicate significant differences between $\mathrm{V}+\mathrm{INC}$ and $\mathrm{V}+\mathrm{PHN}$ or between $\mathrm{V}$ - INC and D- PHN. $* p<0.05 ; * * p<0.01$.

and D- neurons in the PHN, which were obtained in a previous study (Saito et al., 2015). Regarding the intrinsic membrane properties of inhibitory neurons in the INC and the PHN, the input capacitance $(p<0.0001)$, the input resistance $(p<0.0001)$, the spike half-width $(p=0.0097)$, the AHP amplitude ( $\rho=0.0007)$, and the CV of the interspike interval $(p=0.036)$ were significantly different between the $\mathrm{V}+\mathrm{INC}$ neurons and the $\mathrm{V}+\mathrm{PHN}$ neurons (Table 2). With regard to excitatory neurons, the input resistance $(p=0.0002)$, the spike amplitude $(p<0.0001)$, the spike half-width $(p<0.0001)$, the AHP amplitude $(p=$ $0.0063)$, and the CV of the interspike interval $(p=0.0003)$ were significantly different between the $\mathrm{V}$ - INC neurons and the D- PHN neurons (Table 2). These results suggest that both excitatory and inhibitory neurons have different intrinsic properties between the INC and the PHN. Figure $3, A$ and $B$, shows the distributions of inhibitory (1) and excitatory (2) neurons classified based on the AHP profiles $(A)$ and the firing patterns $(B)$ in the INC. Neurons that exhibited the ADP profile were predominant both in inhibitory and excitatory neurons and this tendency was significant in excitatory neurons. A majority of inhibitory neurons exhibited either the LAT pattern or the FIL pattern, whereas excitatory neurons appeared not to show a preferred firing pattern. The firing pattern represented in Figure 1D4 was observed in one V- INC neuron that was confirmed to be within the INC. Figure 3, $C$ and $D$, shows the proportion of inhibitory (1) and excitatory (2) neurons that exhibited each AHP profile and each firing pattern in the INC (red) and the PHN (blue). Excitatory neurons exhibiting the S- profile were not seen in the INC or the PHN (Fig. 3C2). The percentage of inhibitory neurons that exhibited the S- profile and the percentage of excitatory neurons that exhibited the $\mathrm{S}+$ profile tended to be higher in the PHN than in the INC. None of the inhibitory neurons in the INC and PHN exhibited the LFR pattern (Fig. 3D1). The percentage of excitatory and inhibitory neurons that exhibited the CON pattern was higher in the PHN than in the INC. The proportion of INC and PHN neurons that exhibited the OSC pattern was different between inhibitory and excitatory neurons.

A previous study demonstrated that PHN neurons exhibit spontaneous miniature outward currents (SMOCs; Saito and Yanagawa, 2013) that display slower kinetics than postsynaptic currents and are induced by $\mathrm{Ca}^{2+}$ activated $\mathrm{K}^{+}$channels, which are activated through $\mathrm{Ca}^{2+}$ induced $\mathrm{Ca}^{2+}$ release from the endoplasmic reticulum via ryanodine receptors (Arima et al., 2001; Cui et al., 2004; Klement et al., 2010). Because SMOCs were frequently observed in $\mathrm{V}+\mathrm{PHN}$ neurons (Saito and Yanagawa, 2013), we examined whether the SMOCs were also observed in $\mathrm{V}+$ INC neurons. Of $55 \mathrm{~V}+$ INC neurons, 53 exhibited SMOCs (Fig. 3E1). No significant difference was seen in the frequency of SMOCs of $\mathrm{V}+$ neurons between the INC and the PHN ( $p=0.081$; Fig. 3E2).

\section{EPSC responses to burst stimulation}

We previously demonstrated that under a blockade of inhibitory synaptic transmissions, the application of burst stimulation (100 Hz, 20 pulses) in the vicinity of a recorded neuron within the PHN induced an increase in the frequency of spontaneous EPSCs that lasted for several seconds (Saito and Yanagawa, 2010). This result indicates the presence of local excitatory networks in the $\mathrm{PHN}$, which maintain the increased EPSC frequency. To test whether local excitatory networks also exist in the INC, we investigated spontaneous EPSCs of INC neurons before and after application of burst stimulation. Figure $4 \mathrm{~A}$ shows spontaneous EPSCs of an INC neuron before and after application of burst stimulation (arrow) in the presence of $100 \mu \mathrm{M}$ picrotoxin and $20 \mu \mathrm{M}$ strychnine. Spontaneous EPSCs infrequently occurred before the burst stimulation, but the frequency of EPSCs increased after stimulation. The raster plots and the histogram of EPSC frequency constructed for three recording times showed that the high frequency of EPSCs after burst stimulation gradually decreased with time (Fig. 4A2,A3). The duration of the increased EPSC frequency of this neuron was $1.9 \mathrm{~s}$, which was longer than the duration of the burst stimulation (0.2 s). The EPSC responses were investigated in 17 INC neurons and the mean duration of the increased EPSC frequency was $1.6 \pm 0.7 \mathrm{~s}$. When the durations of the INC neurons were compared to those of the previously investigated PHN neurons ( $n=17,2.2 \pm 0.9 \mathrm{~s}$ ), there was no significant difference in the duration between the INC neurons and the PHN neurons $(p=0.053$; Fig. 4B). This result suggests the presence of local excitatory networks in the INC, which maintain the increased EPSC frequency. In this experiment, we noticed that the EPSC frequency during $1 \mathrm{~s}$ after the burst stimulation was not as high in the INC $(26.4 \pm 2.0$ event/s) compared to in the PHN (31.9 \pm 12.0 event/s). The EPSC frequency before the burst stimulation was not significantly different between INC neurons (5.8 \pm 3.6 event/s) and PHN neu- 
A $1 \mathrm{~V}+$ INC

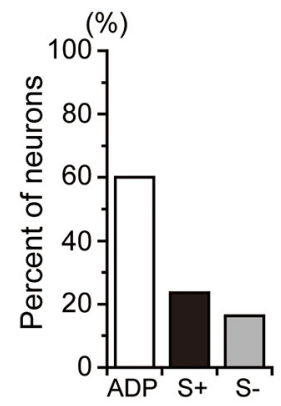

C $1 \mathrm{~V}+$

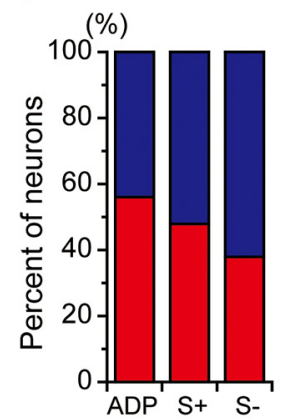

2 V- INC

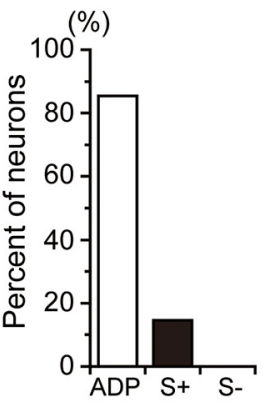

B

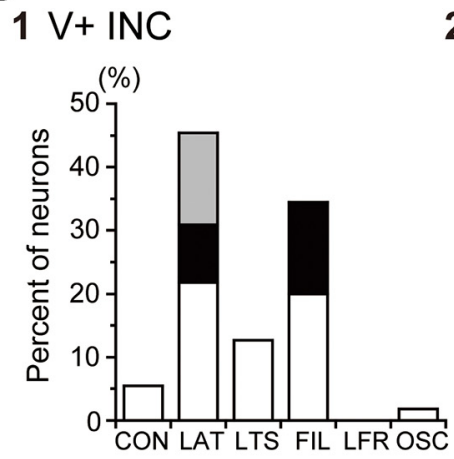

2 V- INC

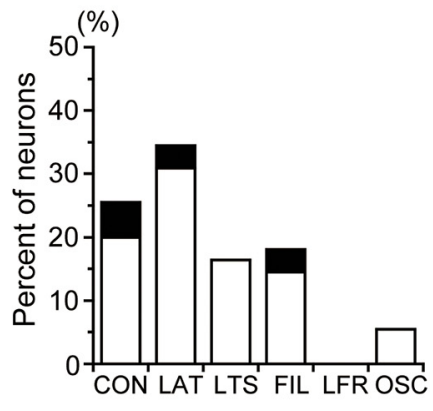

D

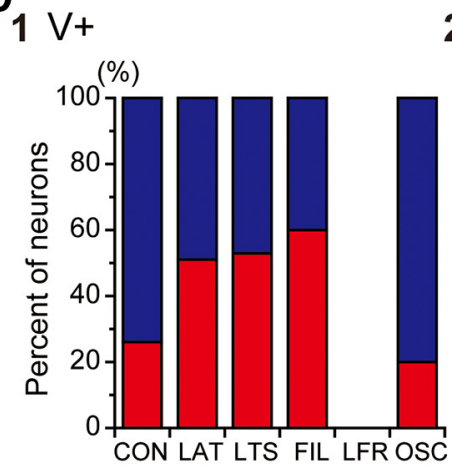

2 V-

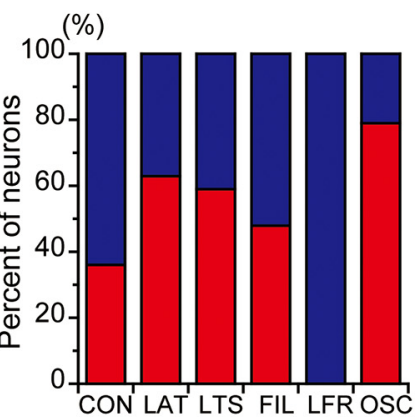

E

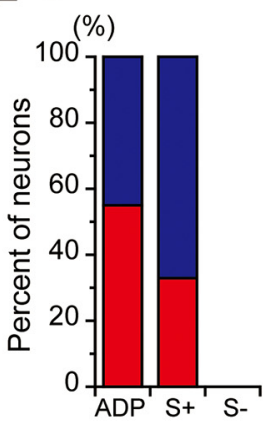

$2 \mathrm{~V}$
2

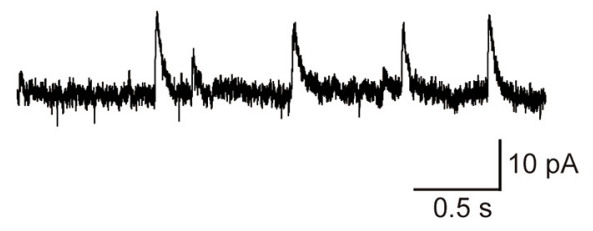

Figure 3. AHP profiles and firing patterns of INC neurons in VGAT-Venus transgenic rats. $\boldsymbol{A}$, $\boldsymbol{B}$, Distributions of Venus-expressing $(\mathrm{V}+\mathrm{INC} ; 1)$ and Venus-nonexpressing (V- INC; 2$)$ neurons classified based on AHP profiles $(\boldsymbol{A})$ and firing patterns $(\boldsymbol{B})$ in the INC. $\boldsymbol{C}, \boldsymbol{D}$, The proportions of INC (red) and PHN (blue) neurons that exhibited each AHP profile (C) or firing pattern (D). The percentages of neurons that exhibited each AHP profile or each firing pattern were normalized to the total percentage of neurons exhibiting each property. E1, SMOCs of a V+ INC neuron. E2, Comparison of the frequency of SMOCs between INC and PHN neurons. The plots indicate data obtained from individual neurons, and the bars represent the average value in the INC (red) and PHN (blue) neurons.

rons $(4.2 \pm 2.0$ event/s, $p=0.28)$. Therefore, the ratio of the EPSC frequency after the burst stimulation to the frequency before the stimulation $\left(\mathrm{F}_{\text {post }} / \mathrm{F}_{\text {pre }}\right)$ was compared between the INC and PHN neurons (Fig. 4C). The $\mathrm{F}_{\text {post }} / \mathrm{F}_{\text {pre }}$ of the INC neurons $(5.0 \pm 2.4)$ was significantly smaller than that of the PHN neurons $(9.3 \pm 6.5, p=$ 0.016).

The evidence that the sustained increase in EPSC frequency (sustained EPSC response) was reduced by the application of NAS suggests the involvement of CPAMPA receptors in the responses (Saito and Yanagawa, 2010). To verify whether CP-AMPA receptors also participate in the sustained EPSC responses in the INC, we investigated the effect of NAS on spontaneous EPSCs of
INC neurons (Fig. 4D). The application of NAS reduced the incidence of EPSCs (Fig. 4D1). Figure 4, D2 and D3, shows comparisons of the maximum EPSC amplitude (2) and the duration of the sustained EPSC responses (3) between the control solution and the solution containing NAS (seven INC neurons were tested). The average amplitude of the maximum EPSC of the INC neurons in the presence of NAS $(21.2 \pm 4.2 \mathrm{pA})$ was significantly smaller than that in the control solution $(29.9 \pm 4.0 \mathrm{pA}, p=$ 0.0005; Fig. 4D2). The duration in the presence of NAS $(1.4 \pm 0.3 \mathrm{~s})$ was also significantly shorter than that in the control solution $(2.0 \pm 0.6 \mathrm{~s}, p=0.011$; Fig. $4 D 3)$. When the reduction in the maximum EPSC amplitude by NAS was compared between INC and PHN neurons (Fig. 4E), 
A

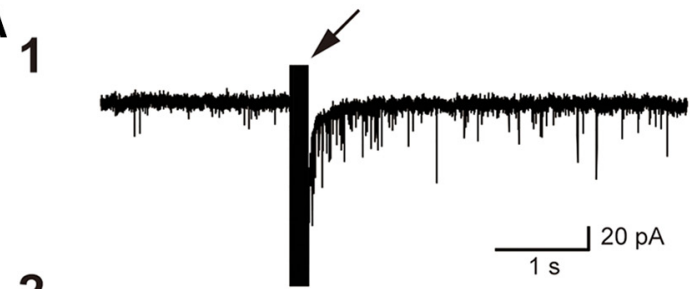

2
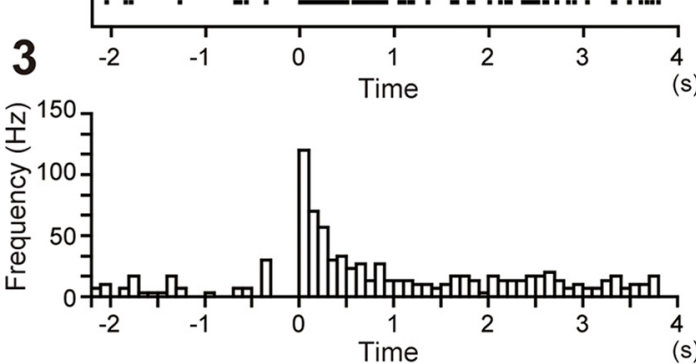

D
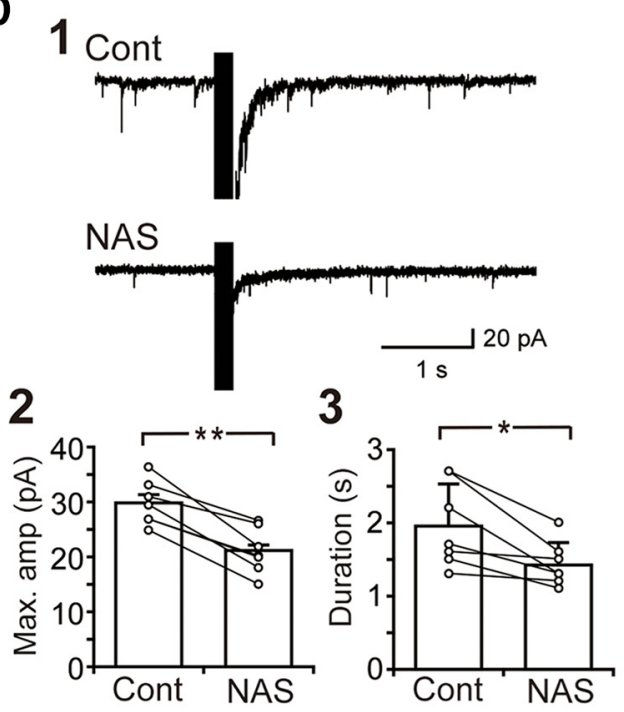

B

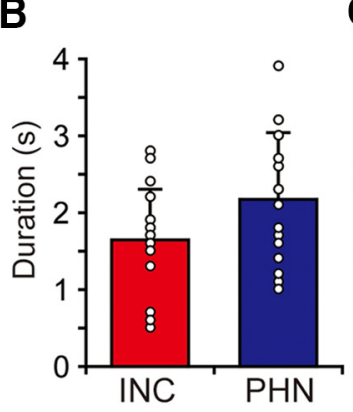

C

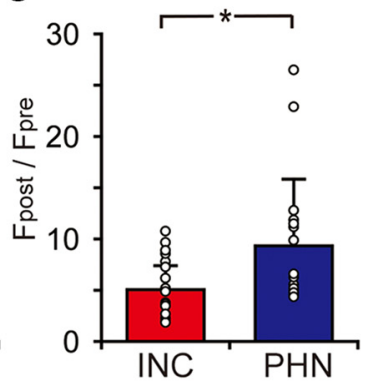

E

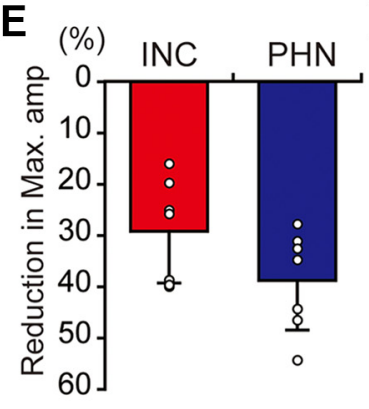

F

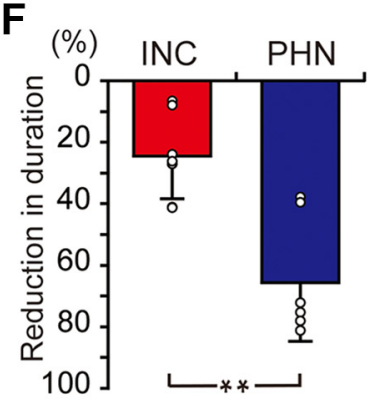

Figure 4. Comparison of EPSC responses to local burst stimulation between INC and PHN neurons. A1, EPSC responses of an INC neuron to burst stimulation (arrow) that was applied in the vicinity of the recorded neuron. A2, Raster plot showing the peak time of each EPSC. The time of the termination of burst stimulation is shown as 0 . Each row in the raster represents one recording. A3, A histogram showing the EPSC frequency against time. Bin width of the histograms is $100 \mathrm{~ms}$. $\boldsymbol{B}, \boldsymbol{C}$, Comparison of the duration of the increased EPSC frequency after the burst stimulation $(\boldsymbol{B})$ and the ratio of the EPSC frequency after the burst stimulation to the frequency before the stimulation $(\boldsymbol{C})$. D1, Spontaneous EPSCs of an INC neuron in a control solution (Cont) and in a solution containing $50 \mu \mathrm{M}$ NAS (NAS). D2, D3, Comparisons of the amplitude of the maximum EPSC (2) and the duration of the sustained EPSC response (3) between a control solution and a solution containing NAS. $\boldsymbol{E}, \boldsymbol{F}$, Comparisons of the percentage reduction in the amplitude of the maximum EPSC $(\boldsymbol{E})$ and the reduction in the duration $(\boldsymbol{F})$ caused by NAS between INC and PHN neurons. Plots indicate data obtained from individual neurons, and the bar represents the average value. Asterisks indicate a significant difference between groups $(* p<0.05 ; * * p<0.01)$.

the percentage of the reduction in INC neurons $(29.2 \pm$ $10.1 \%)$ was not significantly different from that in PHN neurons $(38.7 \pm 9.8 \%, p=0.098)$. However, the reduction in the duration by NAS was significantly smaller in the INC $(24.5 \pm 13.9 \%)$ than in the PHN $(65.7 \pm 18.9 \%, p=$ 0.0087 ; Fig. 4F).

\section{Discussion}

In this study, we investigated electrophysiological membrane properties of INC neurons and the functional structure of excitatory networks in the INC, both of which were not previously characterized using in vitro preparations. Furthermore, we compared the neuronal and network properties of the INC to those of the PHN.

\section{Neuronal properties of the INC and the PHN}

Similar to PHN neurons, a larger population of INC neurons exhibited the ADP profile than other profiles.
However, compared with PHN neurons, the proportion of neurons that exhibited the ADP profile was markedly higher in INC neurons. According to studies of PHN neurons and neurons in the medial vestibular nucleus (MVN), the neurons that exhibit biphasic AHP accompanied by ADP are thought to be phasic-tonic neurons that show irregular firing and nonlinear responses to current stimuli (Ris et al., 2001; Beraneck et al., 2003; Idoux et al., 2006; Saito et al., 2008). Indeed, the CV value of the interspike interval, which can be used as an index of discharge regularity, was higher in INC neurons than in $\mathrm{PHN}$ neurons (Table 2), suggesting that the number of neurons that show irregular discharge is larger in the INC than in the $\mathrm{PHN}$. These findings indicate that most neurons in the INC may be phasic-tonic neurons. The distribution of neurons based on their firing patterns was also different between the INC and the PHN. A striking feature was that no 
neuron that exhibited the LFR pattern was found in the INC. Because the LFR pattern was specific to cholinergic neurons in the PHN (Saito et al., 2015), the absence of cholinergic neurons in the INC may be consistent with the absence of neurons that exhibited the LFR pattern. In the $\mathrm{PHN}$, cholinergic neurons that exhibit the LFR pattern show several unique properties: high input capacitance, spontaneous firing at low frequency, overshooting property in response to ramp currents that reflects the active membrane property, hysteretic frequency-current relationship, and expression of $\mathrm{GABA}_{\mathrm{B}}$ receptors in addition to $\mathrm{GABA}_{\mathrm{A}}$ and glycine receptors (Zhang et al., 2014; Saito and Yanagawa, 2017). Some cholinergic PHN neurons that exhibit the LFR pattern project into the cerebellar cortex (Zhang et al., 2014). Therefore, the presence or absence of cholinergic effects on other brain areas such as the cerebellum via cholinergic neurons that exhibit the LFR pattern and several unique properties may be a notable difference between the INC and the PHN. However, the different neuronal distribution in the INC and the $\mathrm{PHN}$ is not necessarily dependent on the presence of cholinergic neurons in the PHN because the presumed excitatory neurons (V- INC and D- PHN neurons) and inhibitory neurons (V+ INC and V+ PHN neurons) showed different distributions between the INC and the PHN. On the other hand, both INC and PHN neurons exhibited the same AHP profiles and the same firing patterns, except for the LFR pattern. Therefore, the neuronal types in terms of membrane properties are common in the INC and the $\mathrm{PHN}$, but their distributions are different between them. As described above, the proportion of neurons that exhibit phasic and nonlinear properties is inferred to be higher in the INC than in the PHN. This perspective may be supported by the higher percentage of neurons that exhibit the LTS pattern and the lower percentage of neurons that exhibit the CON pattern in the INC than in the PHN. The LTS pattern is mainly caused by T-type $\mathrm{Ca}^{2+}$ currents and often observed in neurons that show nonlinear burst discharge (Jahnsen and Llinás, 1984; McCormick et al., 1985; Serafin et al., 1991; for reviews, see Llinás, 1988; McCormick, 2014), whereas the CON pattern shows linear firing responses to various current stimulations (Saito and Yanagawa, 2017).

Preceding in vitro studies have shown that MVN neurons are classified into discrete types based on their spike shapes: a type that exhibits monophasic AHP (type A), a type that exhibits biphasic AHP (type B), and an intermediate type (type C; Serafin et al., 1991; Johnston et al., 1994; Beraneck et al., 2003; Camp et al., 2006). Based on previous MVN studies investigating the ionic mechanisms of each AHP profile, the fast component of the AHP is caused by A-type $\mathrm{K}^{+}$currents and/or large conductancetype $\mathrm{Ca}^{2+}$-dependent $\mathrm{K}^{+}$currents, whereas the slow component of the AHP is caused mainly by small conductance-type $\mathrm{Ca}^{2+}$-dependent $\mathrm{K}^{+}$currents (Serafin et al., 1991; Johnston et al., 1994; Smith et al., 2002; Saito et al., 2008). The ADP is believed to be caused by $\mathrm{Ca}^{2+}$ dependent nonselective currents (Haj-Dahmane and Andrade, 1997). In addition to the AHP profiles, our previous studies provided an alternative classification of MVN neu- rons based on firing pattern (Takazawa et al., 2004; Saito and Ozawa, 2007). The firing patterns of MVN neurons are mostly similar to those of PHN neurons except for the OSC pattern that has not been observed in MVN neurons (Takazawa et al., 2004; Zhang et al., 2014). Therefore, the CON, LAT, LTS, and FIL patterns are common firing pattern to PHN, INC, and MVN neurons. In our previous studies, a plateau-like potential and a large phase shift were not observed in most PHN neurons (Shino et al., 2008, 2011; Saito et al., 2015; Saito and Yanagawa, 2017), suggesting that the signals directing gaze holding are not generated solely by the intrinsic properties of the individual neurons in the neural integrator. Therefore, the network properties are essential to generate gaze holding signals, and how individual neurons are embedded in the integrator networks is important. Regarding the networks in the PHN, cascade-like connections from velocitycoding phasic neurons to position-coding tonic neurons have been proposed (Escudero et al., 1992; DelgadoGarcía et al., 2006). Based on the firing patterns, neurons that exhibit the CON, LAT, and FIL patterns fire tonically, whereas neurons that exhibit the LTS pattern, which corresponds to the firing pattern of $B+$ LTS MVN neurons (Serafin et al., 1991; Sekirnjak and du Lac, 2002; Camp et al., 2010), show phasic activity. Therefore, when the neurons are embedded in the cascade-like connections, the signals from the premotor areas reach the LTS type and are transmitted to the CON, LAT, and FIL types. Neurons that exhibit the OSC pattern were observed in the PHN and INC but not in the MVN. This neuron type is similar to type D neurons reported by Idoux et al. (2006), with respect to the oscillatory firing (Saito et al., 2015). Type $D$ neurons show bistable plateau-like responses through an NMDA-dependent mechanism, which may be used for the persistency of neural activities in the integrator network. Therefore, the OSC type may play an instrumental role in the integrator networks in the PHN and the INC.

\section{Excitatory network properties of the INC and the PHN}

Gaze holding is supported by tonic activity that is produced via the neural integrator (Robinson, 1975, 1989; Fukushima et al., 1992; Fukushima and Kaneko, 1995; Moschovakis, 1997; Leigh and Zee, 2015). Experimental findings suggest that positive feedback circuits through contralateral integrator regions and cerebellar circuits (Aksay et al., 2001, 2003, 2007; Leigh and Zee, 2015) and the sustained depolarization of PHN neurons mediated by cholinergic inputs (Navarro-López Jde et al., 2004, 2005) participate in tonic activity. In addition, a previous study suggests the contribution of the sustained activation of local excitatory networks to tonic activity (Saito and Yanagawa, 2010). In the present study, analysis of spontaneous EPSCs of INC neurons revealed that the frequency of EPSCs after burst stimulation increased for a few seconds. This enhancement in EPSC frequency following burst stimulation is similar to the sustained EPSC response that was observed in PHN neurons (Saito and Yanagawa, 2010), suggesting that local excitatory net- 
works that activate the sustained EPSC response also exist in the INC. However, the fact that the increase in EPSC frequency after the burst stimulation was not as drastic in the INC compared to the PHN raises a possibility that the number of neurons that participates in excitatory networks and/or the degree of the excitatory connections in the INC may be smaller than those in the $\mathrm{PHN}$. It has been shown that both the PHN and the INC show reciprocal connections with the vestibular nuclei (Fukushima, 1987; McCrea and Horn, 2006; Leigh and Zee, 2015). Therefore, part of the MVN adjacent to the $\mathrm{PHN}$ also participates in the horizontal integrator (Cannon and Robinson, 1987; McFarland and Fuchs, 1992; Sylvestre et al., 2003). A study in the monkey showed that transection of the medial longitudinal fasciculus, which includes the fibers participating in connections between the vestibular nuclei and the INC, results in an impairment of gaze holding after a vertical saccade (Evinger et al., 1977). These findings suggest that the networks to the vestibular nuclei are necessary for the neural integrator to sufficiently function. The moderate increase in the EPSC frequency of INC neurons after the burst stimulation may be attributed to the slice preparations, as the networks between the INC and the vestibular nuclei are disconnected. Therefore, activation of the reverberating circuits between the INC and the vestibular nuclei may be necessary for activating the excitatory networks of the neural integrator for vertical gaze holding. On the other hand, sustained EPSC responses and a drastic increase in EPSC frequency were observed even when the PHN was isolated from other brainstem regions by dissection (Saito and Yanagawa, 2010). This finding suggests that the excitatory networks of the neural integrator for horizontal gaze holding can be activated by recurrent networks within the PHN.

A previous study showed that activation of excitatory networks in the PHN are mediated by CP-AMPA receptors (Saito and Yanagawa, 2010). The burst inputs proportional to velocity signals from premotor burst neurons cause cumulative increases in intracellular $\mathrm{Ca}^{2+}$ concentrations of PHN neurons by repetitive activation of CPAMPA receptors. The increase in the $\mathrm{Ca}^{2+}$ may activate calcium-dependent nonselective cation (CAN) channels, which show slow deactivation kinetics (Morisset and Nagy, 1999; Di Prisco et al., 2000; Fransén et al., 2006). CAN channel-dependent sustained depolarization may persistently activate PHN networks (Saito and Yanagawa, 2010). However, this scenario may not be necessarily applicable to INC networks, because the contribution of CP-AMPA receptors on the sustained EPSC responses was not as great in INC neurons as in PHN neurons (Fig. $4 F$ ). Although we did not test other mechanisms regarding the sustained EPSC responses in the INC, the present findings imply different mechanisms for the generation of sustained activities between the PHN and the INC. In this study, we found different neuronal distributions and different properties of excitatory networks between the PHN and the INC. Because the PHN and the INC show reciprocal connections (McCrea and Horn, 2006; Leigh and Zee, 2015), clarifying how these nuclei interact is neces- sary for determining the network mechanisms of these integrators.

\section{References}

Aksay E, Gamkrelidze G, Seung HS, Baker R, Tank DW (2001) In vivo intracellular recording and perturbation of persistent activity in a neural integrator. Nat Neurosci 4:184-193. CrossRef

Aksay E, Baker R, Seung HS, Tank DW (2003) Correlated discharge among cell pairs within the oculomotor horizontal velocity-toposition integrator. J Neurosci 23:10852-10858. Medline

Aksay E, Olasagasti I, Mensh BD, Baker R, Goldman MS, Tank DW (2007) Functional dissection of circuitry in a neural integrator. Nat Neurosci 10:494-504. CrossRef Medline

Arima J, Matsumoto N, Kishimoto K, Akaike N (2001) Spontaneous miniature outward currents in mechanically dissociated rat Meynert neurons. J Physiol 534:99-107. Medline

Arnold DB, Robinson DA (1997) The oculomotor integrator: testing of a neural network model. Exp Brain.Res 113:57-74. Medline

Beraneck M, Hachemaoui M, Idoux E, Ris L, Uno A, Godaux E, Vidal PP, Moore LE, Vibert N (2003) Long-term plasticity of ipsilesional medial vestibular nucleus neurons after unilateral labyrinthectomy. J Neurophysiol 90:184-203. CrossRef Medline

Bobker DH, Williams JT (1990) Serotonin-mediated inhibitory postsynaptic potential in guinea-pig prepositus hypoglossi and feedback inhibition by serotonin. J Physiol 422:447-462. Medline

Bobker DH, Williams JT (1995) The serotonergic inhibitory postsynaptic potential in prepositus hypoglossi is mediated by two potassium currents. J Neurosci 15:223-229. Medline

Büttner U, Büttner-Ennever JA (2006) Present concepts of oculomotor organization. Prog Brain Res 151:1-42. CrossRef Medline

Camp AJ, Callister RJ, Brichta AM (2006) Inhibitory synaptic transmission differs in mouse type $A$ and $B$ medial vestibular nucleus neurons in vitro. J Neurophysiol 95:3208-3218. CrossRef

Camp AJ, Lim R, Anderson WB, Schofield PR, Callister RJ, Brichta AM (2010) Attenuated glycine receptor function reduces excitability of mouse medial vestibular nucleus neurons. Neuroscience 170:348-360. CrossRef Medline

Cannon SC, Robinson DA (1985) An improved neural-network model for the neural integrator of the oculomotor system: more realistic neuron behavior. Biol Cybern 53:93-108. Medline

Cannon SC, Robinson DA (1987) Loss of the neural integrator of the oculomotor system from brain stem lesions in monkey. J Neurophysiol 57:1383-1409. Medline

Cannon SC, Robinson DA, Shamma S (1983) A proposed neural network for the integrator of the oculomotor system. Biol Cybern 49:127-136. Medline

Chimoto S, Iwamoto Y, Yoshida K (1999) Projections and firing properties of down eye-movement neurons in the interstitial nucleus of Cajal in the cat. J Neurophysiol 81:1199-1211. Medline

Crawford JD, Cadera W, Vilis T (1991) Generation of torsional and vertical eye position signals by the interstitial nucleus of Cajal. Science 252:1551-1553. Medline

Cui G, Okamoto T, Morikawa H (2004) Spontaneous opening of T-type $\mathrm{Ca} 2+$ channels contributes to the irregular firing of dopamine neurons in neonatal rats. J Neurosci 24:11079-11087. CrossRef Medline

Delgado-García JM, Vidal PP, Gómez C, Berthoz A (1989) A neurophysiological study of prepositus hypoglossi neurons projecting to oculomotor and preoculomotor nuclei in the alert cat. Neuroscience 29:291-307. Medline

Delgado-García JM, Yajeya J, Navarro-López Jde D (2006) A cholinergic mechanism underlies persistent neural activity necessary for eye fixation. Prog Brain Res 154:211-224. CrossRef Medline

Draye JP, Cheron G, Libert G, Godaux E (1997) Emergence of clusters in the hidden layer of a dynamic recurrent neural network. Biol Cybern 76:365-374. CrossRef Medline

Escudero M, de la Cruz RR, Delgado-García JM (1992) A physiological study of vestibular and prepositus hypoglossi neurons project- 
ing to the abducens nucleus in the alert cat. J Physiol 458:539560. Medline

Evinger LC, Fuchs AF, Baker R (1977) Bilateral lesions of the medial longitudinal fasciculus in monkeys: effects on the horizontal and vertical components of voluntary and vestibular induced eye movements. Exp Brain Res 28:1-20. Medline

Faul F, Erdfelder E, Lang AG, Buchner A (2007) G*Power 3: a flexible statistical power analysis program for the social, behavioral, and biomedical sciences. Behav Res Methods 39:175-191. Medline

Fransén E, Tahvildari B, Egorov AV, Hasselmo ME, Alonso AA (2006) Mechanism of graded persistent cellular activity of entorhinal cortex layer $V$ neurons. Neuron 49:735-746. CrossRef

Fukushima K (1987) The interstitial nucleus of Cajal and its role in the control of movements of head and eyes. Prog Neurobiol 29:107192. Medline

Fukushima K (1991) The interstitial nucleus of Cajal in the midbrain reticular formation and vertical eye movement. Neurosci Res 10: 159-187. Medline

Fukushima K, Kaneko CR (1995) Vestibular integrators in the oculomotor system. Neurosci Res 22:249-259. Medline

Fukushima K, Harada C, Fukushima J, Suzuki Y (1990a) Spatial properties of vertical eye movement-related neurons in the region of the interstitial nucleus of Cajal in awake cats. Exp Brain Res 79:25-42.

Fukushima K, Fukushima J, Harada C, Ohashi T, Kase M (1990b) Neuronal activity related to vertical eye movement in the region of the interstitial nucleus of Cajal in alert cats. Exp Brain Res 79:4364.

Fukushima K, Kaneko CR, Fuchs AF (1992) The neuronal substrate of integration in the oculomotor system. Prog Neurobiol 39:609-639. Medline

Galiana HL, Outerbridge JS (1984) A bilateral model for central neural pathways in vestibuloocular reflex. J Neurophysiol 51:210-241. Medline

Giolli RA, Peterson GM, Ribak CE, McDonald HM, Blanks RH, Fallon $\mathrm{JH}(1985)$ GABAergic neurons comprise a major cell type in rodent visual relay nuclei: an immunocytochemical study of pretectal and accessory optic nuclei. Exp Brain Res 61:194-203. CrossRef

Haj-Dahmane S, Andrade R (1997) Calcium-activated cation nonselective current contributes to the fast afterdepolarization in rat prefrontal cortex neurons. J Neurophysiol 78:1983-1989. Medline

Helmchen C, Rambold H, Fuhry L, Büttner U (1998) Deficits in vertical and torsional eye movements after uni- and bilateral muscimol inactivation of the interstitial nucleus of Cajal of the alert monkey. Exp Brain Res 119:436-452. Medline

Horn AK, Helmchen C, Wahle P (2003) GABAergic neurons in the rostral mesencephalon of the macaque monkey that control vertical eye movements. Ann NY Acad Sci 1004:19-28. Medline

Idoux E, Serafin M, Fort P, Vidal PP, Beraneck M, Vibert N, Mühlethaler M, Moore LE (2006) Oscillatory and intrinsic membrane properties of guinea pig nucleus prepositus hypoglossi neurons in vitro. J Neurophysiol 96:175-196. CrossRef Medline

Idoux $E$, Eugène D, Chambaz A, Magnani C, White JA, Moore LE (2008) Control of neuronal persistent activity by voltagedependent dendritic properties. J Neurophysiol 100:1278-1286. CrossRef

Izawa Y, Sugiuchi Y, Shinoda Y (2007) Neural organization of the pathways from the superior colliculus to trochlear motoneurons. J Neurophysiol 97:3696-3712. CrossRef Medline

Jahnsen H, Llinás R (1984) Electrophysiological properties of guineapig thalamic neurons: an in vitro study. J Physiol 349:205-226. Medline

Johnston AR, MacLeod NK, Dutia MB (1994) Ionic conductances contributing to spike repolarization and after-potentials in rat medial vestibular nucleus neurones. J Physiol 481:61-77. CrossRef

King WM, Fuchs AF, Magnin M (1981) Vertical eye movement-related responses of neurons in midbrain near intestinal nucleus of Cajal. $J$ Neurophysiol 46:549-562. Medline

Klement G, Druzin M, Haage D, Malinina E, Arhem P, Johansson S (2010) Spontaneous ryanodine-receptor-dependent $\mathrm{Ca} 2+$-activated $\mathrm{K}+$ currents and hyperpolarizations in rat medial preoptic neurons. J Neurophysiol 103:2900-2911. CrossRef Medline

Kolkman KE, Moghadam SH, du Lac S (2011) Intrinsic physiology of identified neurons in the prepositus hypoglossi and medial vestibular nuclei. J Vestib Res 21:33-47. CrossRef Medline

Lee MM, Arrenberg AB, Aksay ER (2015) A structural and genotypic scaffold underlying temporal integration. J Neurosci 35:79037920. CrossRef Medline

Leigh RJ, Zee DS (2015) The neurology of eye movements. Oxford: Oxford University Press.

Llinás R (1988) The intrinsic electrophysiological properties of mammalian neurons: insights into central nervous system function. Science 242:1654-1664. Medline

Lopez-Barneo J, Darlot C, Berthoz A, Baker R (1982) Neuronal activity in prepositus nucleus correlated with eye movement in the alert cat. J Neurophysiol 47:329-352. Medline

Major G, Tank D (2004) Persistent neural activity: prevalence and mechanisms. Curr Opin Neurobiol 14:675-684. CrossRef Medline

McCormick DA (2014) Membrane potential and action potential. In: From molecules to networks: an introduction to cellular and molecular neuroscience, Ed 3 (Byrne JH, Heidelberger R, Waxham MN eds), pp 351-376. San Diego: Academic.

McCormick DA, Connors BW, Lighthall JW, Prince DA (1985) Comparative electrophysiology of pyramidal and sparsely spiny stellate neurons of the cortex. J Neurophysiol 54:782-806. Medline

McCrea RA, Horn AK (2006) Nucleus prepositus. Prog Brain Res 151:205-230. CrossRef Medline

McFarland JL, Fuchs AF (1992) Discharge patterns in nucleus prepositus hypoglossi and adjacent medial vestibular nucleus during horizontal eye movement in behaving macaques. J Neurophysiol 68:319-332. Medline

Miller NR (1985) The neural control of eye movements. In: Walsh and Hoyt's clinical neuro-ophthalmology, Vol 2, Ed 4. Baltimore: Williams \& Wilkins.

Morisset V, Nagy F (1999) lonic basis for plateau potentials in deep dorsal horn neurons of the rat spinal cord. J Neurosci 19:73097316. Medline

Moschovakis AK (1997) The neural integrators of the mammalian saccadic system. Front Biosci 2:D552-D577. Medline

Nagai T, Ibata K, Park ES, Kubota M, Mikoshiba K, Miyawaki A (2002) $A$ variant of yellow fluorescent protein with fast and efficient maturation for cell-biological applications. Nat Biotechnol 20:87-90. CrossRef Medline

Nakao S, Shiraishi Y (1985) Direct excitatory and inhibitory synaptic inputs from the medial mesodiencephalic junction to motoneurons innervating extraocular oblique muscles in the cat. Exp Brain Res 61:62-72. Medline

Navarro-López Jde D, Alvarado JC, Márquez-Ruiz J, Escudero M, Delgado-García JM, Yajeya J (2004) A cholinergic synaptically triggered event participates in the generation of persistent activity necessary for eye fixation. J Neurosci 24:5109-5118. CrossRef Medline

Navarro-López Jde D, Delgado-García JM, Yajeya J (2005) Cooperative glutamatergic and cholinergic mechanisms generate shortterm modifications of synaptic effectiveness in prepositus hypoglossi neurons. J Neurosci 25:9902-9906. CrossRef Medline

Paxinos G, Watson C (2007) The rat brain in stereotaxic coordinates, Ed 6. San Diego: Academic Press.

Ris L, Hachemaoui M, Vibert N, Godaux E, Vidal PP, Moore LE (2001) Resonance of spike discharge modulation in neurons of the guinea pig medial vestibular nucleus. J Neurophysiol 86:703-716. Medline

Robinson DA (1975) Oculomotor control signals. In: Basic mechanisms of ocular motility and their clinical implications (Lennerstrand G, Bach-y-Rita P, eds), pp 337-374. Oxford: Pergamon.

Robinson DA (1989) Integrating with neurons. Ann Rev Neurosci 12:33-45. CrossRef Medline

Rutherford JG, Gwyn DG (1982) A light and electron microscopic study of the interstitial nucleus of Cajal in rat. J Comp Neur 205:327-340. CrossRef Medline 
Saito Y, Ozawa S (2007) Membrane properties of rat medial vestibular nucleus neurons in vivo. Neurosci Res 59:215-223. CrossRef Medline

Saito Y, Yanagawa Y (2010) Synaptic mechanism for the sustained activation of oculomotor integrator circuits in the rat prepositus hypoglossi nucleus: contribution of $\mathrm{Ca}^{2+}$-permeable AMPA receptors. J Neurosci 30:15735-15746. CrossRef Medline

Saito Y, Yanagawa Y (2013) $\mathrm{Ca}^{2+}$-activated ion currents triggered by ryanodine receptor-mediated $\mathrm{Ca}^{2+}$ release control the firing of inhibitory neurons in the prepositus hypoglossi nucleus. J Neurophysiol 109:389-404. CrossRef

Saito Y, Yanagawa Y (2017) Distinct response properties of rat prepositus hypoglossi nucleus neurons classified on the basis of firing patterns. Neurosci Res 121:18-28. CrossRef Medline

Saito Y, Takazawa T, Ozawa S (2008) Relationship between afterhyperpolarization profiles and the regularity of spontaneous firings in rat medial vestibular nucleus neurons. Eur J Neurosci 28:288-298. CrossRef Medline

Saito Y, Shino M, Yanagawa Y (2012) Characterization of ionic channels underlying the specific firing pattern of a novel neuronal subtype in the rat prepositus hypoglossi nucleus. Neurosci Res 73:32-41. CrossRef Medline

Saito Y, Zhang Y, Yanagawa Y (2015) Electrophysiological and morphological properties of neurons in the prepositus hypoglossi nucleus that express both ChAT and VGAT in a double-transgenic rat model. Eur J Neurosci 41:1036-1048. CrossRef

Schwindt PC, Precht W, Richter A (1974) Monosynaptic excitatory and inhibitory pathways from medial midbrain nuclei to trochlear motoneurons. Exp Brain Res 20:223-238. Medline

Sekirnjak C, du Lac S (2002) Intrinsic firing dynamics of vestibular nucleus neurons. J Neurosci 22:2083-2095. Medline

Serafin M, de Waele C, Khateb A, Vidal PP, Mühlethaler M (1991) Medial vestibular nucleus in the guinea-pig. II. Ionic basis of the intrinsic membrane properties in brainstem slices. Exp Brain Res 84:426-433. Medline

Seung HS, Lee DD, Reis BY, Tank DW (2000) Stability of the memory of eye position in a recurrent network of conductance-based model neurons. Neuron 26:259-271. Medline

Shino M, Ozawa S, Furuya N, Saito Y (2008) Membrane properties of excitatory and inhibitory neurons in the rat prepositus hypoglossi nucleus. Eur J Neurosci 27:2413-2424. CrossRef Medline
Shino M, Kaneko R, Yanagawa Y, Kawaguchi Y, Saito Y (2011) Electrophysiological characteristics of inhibitory neurons of the prepositus hypoglossi nucleus as analyzed in Venus-expressing transgenic rats. Neuroscience 197:89-98. CrossRef Medline

Smith MR, Nelson AB, DU Lac S (2002) Regulation of firing response gain by calcium-dependent mechanisms in vestibular nucleus neurons. J Neurophysiol 87:2031-2042. CrossRef Medline

Sugiuchi Y, Takahashi M, Shinoda Y (2013) Input-output organization of inhibitory neurons in the interstitial nucleus of Cajal projecting to the contralateral trochlear and oculomotor nucleus. J Neurophysiol 110:640-657. CrossRef Medline

Sylvestre PA, Choi JT, Cullen KE (2003) Discharge dynamics of oculomotor neural integrator neurons during conjugate and disjunctive saccades and fixation. J Neurophysiol 90:739-754. CrossRef Medline

Tago H, McGeer PL, McGeer EG, Akiyama H, Hersh LB (1989) Distribution of choline acetyltransferase immunopositive structures in the rat brainstem. Brain Res 495:271-297. CrossRef

Takazawa T, Saito Y, Tsuzuki K, Ozawa S (2004) Classification of neuron types based on molecular, electrophysiological, and morphological characteristics in the rat medial vestibular nucleus. $J$ Neurophysiol 92:3106-3120. CrossRef

Uematsu M, Hirai H, Karube F, Ebihara S, Kato M, Abe K, Obata K, Yoshida S, Hirabayashi M, Yanagawa Y, Kawaguchi Y (2008) Quantitative chemical composition of cortical GABAergic neurons revealed in transgenic venus-expressing rats. Cereb Cortex 18: 315-330. CrossRef

Di Prisco GV, Pearlstein E, Le Ray D, Robitaille R, Dubuc R (2000) A cellular mechanism for the transformation of a sensory input into a motor command. J Neurosci 20:8169-8176. Medline

Zhang Y, Kaneko R, Yanagawa Y, Saito Y (2014) The vestibulo- and preposito-cerebellar cholinergic neurons of a ChAT-tdTomato transgenic rat exhibit heterogeneous firing properties and the expression of various neurotransmitter receptors. Eur $\mathrm{J}$ Neurosci 39:1294-1313. CrossRef Medline

Zhang Y, Yanagawa Y, Saito Y (2016) Nicotinic acetylcholine receptor-mediated responses in medial vestibular and prepositus hypoglossi nuclei neurons showing distinct neurotransmitter phenotypes. J Neurophysiol 115:2649-2657. CrossRef Medline 